\title{
Index-Based Cost-Effectiveness Analysis vs. Least-Cost River Basin Optimization Model: comparison in the selection of a programme of measures at the river basin scale
}

\author{
Corentin GIRARD ${ }^{a}$, Jean-Daniel RINAUDO ${ }^{b}$, and Manuel PULIDO-VELAZQUEZ ${ }^{c}$ \\ ${ }^{a}$ Research Institute of Water and Environmental Engineering (IIAMA), Universitat Politècnica de València, Camino \\ de Vera s/n, Valencia, 46022 Spain. cogi@posgrado.upv.es (corresponding author) \\ ${ }^{\mathrm{b}}$ BRGM, French Geological Survey, 1039, Rue de Pinville, 34000, Montpellier, France. jd.rinaudo@brgm.fr \\ ${ }^{\mathrm{C}}$ Research Institute of Water and Environmental Engineering (IIAMA), Universitat Politècnica de València, Camino \\ de Vera s/n,46022 Valencia, Spain mapuve@upv.es
}

\begin{abstract}
Increasing water scarcity challenges conventional approaches to managing water resources. More holistic tools and methods are required to support the integrated planning and management of fresh water resources at the river basin level. This paper compares an index-based cost-effectiveness analysis (IBCEA) with a least-cost river basin optimization model (LCRBOM). Both methods are applied to a real case study to design a cost-effective portfolio of water demand and supply management measures that ensures compliance with water supply and environmental targets. The IBCEA is a common approach to select programmes of measures in the implementation of the EU Water Framework Directive. We describe its limitations in finding a least-cost solution at the river basin level and highlight the benefits from implementing a LCRBOM. Both methods are compared in a real case study, the Orb river basin, in the south of France. The performances of the programmes of measures selected by the two methods are compared for the same annual equivalent cost. By ignoring the spatial and temporal variability of water availability and water demands in the river basin and the interconnection among its elements, the aggregated approach used in the standard IBCEA can miss more cost-effective solutions at the river basin scale.
\end{abstract}

Highlights:

- The limits of IBCEA at the river basin scale are highlighted

- The methodological steps required to develop an IBCEA and a Least-Cost River Basin Optimization Model are presented

- The advantages of both methods to support water resources planning are contrasted

- A method for the comparison of both approaches is described

- The implementation of the approaches in a real case study are discussed

Key words: Cost-effectiveness analysis; Least-cost optimization; Water Framework Directive; Programme of Measures; water conservation measures. 


\section{Introduction}

In Europe, in a context of increasing water scarcity (EEA 2012a, 2012b), water managers and planners acknowledge the need to ground quantitative management of fresh water resources (both surface and groundwater resources) on a more solid foundation in order to satisfy increasing demands and achieve environmental objectives (EC, 2012). In addition to the definition of the environmental flows requirement, there is a growing consensus that reaching environmental objectives will also rely on the capacity to combine water demand management measures with supply from new water resources (EC, 2007; EEA, 2012b).

The use of economic methods in the selection of water management measures is not new. In the US, Cost-Benefit Analysis (CBA) has been a standard in federal water projects since the 1936 US Flood Control Act made it a requirement to assess that the benefits, "to whomsoever they accrue", are in excess of the estimated costs. However, the difficulty of correctly applying CBA to water management programmes in systems with complex physical and economic interactions "weakens policymakers' confidence in comprehensive economic assessments at the basin scale” (Ward, 2009; Rinaudo and Aulong, 2014). Alternatively, a Cost-Effectiveness Analysis (CEA) has often been used to select programmes of measures, bypassing the valuation of non-market environmental benefits (and related controversies over non-market benefit valuation methods) and secondary benefits (Griffin, 1998). CEA requires only that the management targets be met at the minimum cost.

Following that direction, the policy approach adopted in Europe consists in defining water quality and environmental objectives based on biophysical criteria only. Once the objectives have been set, water managers and planners are required to conduct "an economic analysis that shall contain enough information to make judgments about the most cost-effective combination of measures to be included in the programme of measures" to meet these objectives (EC, 2000). Although no direct reference is made to the method, EU policy implementation guidelines clearly call for the use of Cost-Effectiveness Analysis (WATECO, 2003). The approach has been recommended in most national guidelines, reports and academic papers (Interwies et al., 2004, 2005; van Engelen et al., 2008; Heinz et al., 2009; Berbel et al., 2011). In most of the existing studies, the CEA approach consists of ranking measures at the basin scale based on a single indicator of cost-effectiveness (what we refer to as Index-Based Cost- 
Effectiveness Analysis, IBCEA), estimated as total cost divided by total effect (ACTEON, 2011). The main limitation of the IBCEA approach is that it measures effectiveness as a reduction in the pressure (decrease in pollutant discharge concentration from point source pollution, or decrease in water abstraction), whereas objectives are defined in terms of impacts (good chemical and good environmental status of the water bodies, the latter often linked to in-stream environmental flow requirements), (Berbel, et al., 2011, Balana et al., 2011; Martin-Ortega, 2012). These limitations have mainly been highlighted in the context of water quality issues, but here we extend this reflection on the use of CEA by focusing on water quantity management challenges in a context of water scarcity.

In this paper, we argue that the method adopted to perform the economic analysis for the selection of a programme of measures (PoM) must be context-specific and adapted to the type of decision it will inform. A preliminary screening of measures based on a basin-wide index-based cost-effectiveness ratio can certainly be a useful support in the development of the main lines of quantitative water management strategies. However, it can be misleading when identifying cost-effective solutions at the basin scale for several reasons. First, the cost and effectiveness of measures vary significantly with the location within the watershed, depending on the specific technical and economic circumstances under which they are implemented. This problem can be solved by calculating the cost-effectiveness ratio for each measure in each specific location or context, provided sufficient data are available. Second, river basin management plans usually target multiple quantitative management objectives simultaneously (not to mention quality objectives); for example, minimum in-stream flow requirements at different river reaches. The effectiveness of measures should then be assessed by taking into account their contribution to these different objectives along the connected water bodies, considering the spatial and temporal specificities of the basin. This requires integrating the physical characteristics of the water bodies (interconnections, stream/aquifer interactions, reservoir releases, return flows, system operating rules, etc.) to capture the spatial (upstream-downstream interactions) and temporal (hydrological and demand variability) dimensions of the problem, as is done in integrated water resources management models (Wurbs, 1996). The problem to be solved thus becomes more complex than ranking measures according to a single indicator. It can be formalized as a least-cost optimization problem at the river basin scale, where the analyst seeks to identify the optimum combination of measures that (i) minimizes costs, while (ii) meeting several interrelated management constraints, (iii) associated with a given probability of failure over time (performance indicators). Solving this kind of problem requires implementing a computer- 
based optimization model that integrates hydrology and economics; tools that belong to the family of integrated water resource management models (Loucks and Van Beck, 2005) and could be considered as a type of hydro-economic model, HEM, (Heinz et al., 2007; Harou et al., 2009; Brouwer and Hofkes, 2008; Pulido-Velazquez et al., 2008) taking a broad definition of HEM.

This paper aims to illustrate the implications of shifting from an Index-Based Cost-Effectiveness Analysis to a more comprehensive and integrated Least-Cost River Basin Optimization Model (LCRBOM). IBCEA and LCRBOM are two methodologies usually implemented by two distinct scientific communities (economists and engineers with expertise on system analysis) in the field of water resources. The originality of the paper lies in the operational implementation and the comparison of the two methods in a single real case study. The quantitative method proposed for comparing the results obtained with the two approaches is also innovative. The study highlights the limits of the commonly recommended approach of the IBCEA and provides scientific recommendations to better support the development of a least-cost strategy at the river basin scale. The two methods have been implemented in the same case study area in Southern France (Orb river basin). In this river basin, water scarcity will become significant under the projected impact of climate and demand changes. It provides a useful example to illustrate the gains from shifting from an IBCEA to a LCRBOM. The paper highlights policy questions that can be answered by each methodology, as well as their requirements in terms of data and expertise.

The paper is organized as follows. In the next section, we present both methods and we draw a first theoretical comparison (section 2). We then describe the case study area and the policy context in which they have been implemented and compared (section 3). The main steps and results of the two methodologies deployed are described in section 4 and 5. The results of the LCRBOM are presented and compared with those obtained with the IBCEA in section 6 . We then formulate recommendations on the use of each method, taking policy application into account (section 7).

\section{Methods}

\subsection{Index-Based Cost-Effectiveness Analysis (IBCEA)}

Cost-effectiveness analysis (CEA) can be broadly defined as a method for comparing alternative policy in view of minimizing the cost of achieving a desired objective (Garber and Phelps, 1997). The 
appropriateness of CEA as a decision rule to address the complexity of water management problems in comparison to other types of analysis (Cost-Benefit Analysis, Multi-criteria, etc.) is clearly an issue (Messner, 2006; Martin-Ortega, 2012).

Nevertheless, considering the current policy requirement of the EU-WFD, we principally discuss the relevance of an Indexed Based Cost-Effectiveness Analysis (IBCEA) as a methodological scientific prescription to provide enough information to make a judgment on the most cost-effective combination of measures to be selected in a programme of measures at the river basin scale.

By IBCEA we refer to the method commonly used by water planners in Europe that consists of ranking and selecting measures based on a single cost-effectiveness criterion, with effectiveness usually measured as an indicator of pressure reduction. The main steps can be summarized as follows. First (step 1), the analyst defines the water quantity target, i.e. the aggregated gap between water demands and available resources (generally at the basin level). Subsequently, supply and demand management measures are identified, as a "catalogue" of measures, and their cost and effectiveness are estimated (step 2). Effectiveness is here simply defined as a pressure reduction, and not based on the final impact of the measures on the water bodies. A single indicator is then defined for each measure, the costeffectiveness ratio (step 3), expressed in a monetary unit per cubic meter of water either saved (demand side measures) or made available (supply side measures). In the next step, measures are ranked according to increasing CEA ratio. Finally, measures are selected following this order (step 4) until the point where the cumulative sum of the effectiveness of the measures (volume of water) equals the gap estimated in the first step. This method is usually applied at the strategic planning stage, without considering the operational management constraints, return flows, water losses, etc. The IBCEA does not deal with the implications of the spatial and temporal dimensions of water availability and water use in the basin. In this study, our focus is clearly on steps 3 and 4 , investing the combination of the measures and bringing insights from a water resources management perspective into the economic analysis. This means that we will discuss the issue of the characterization of the effectiveness of the measures, not of the cost and discounting, which has already been addressed by several authors (Aulong et al., 2009; White et al., 2003). 
Table 1 shows some examples of Cost-Effectiveness Analysis to select demand and/or supply measures in order to solve quantitative water management problems. The methods are classified by the type of quantitative measures they analyse (supply or demand side), the way cost and effectiveness are defined, the scale and the time step of the analysis. In most CEA applications, the analysis of the effectiveness of the measures on the water resources system is limited to their contribution towards reducing the deficit between supply and demand at a fixed time step (annual or peak season) at a river basin or regional scale. The effectiveness of the measures is based on their effects on pressure reduction; a set of measures are then selected to fill the gap. IBCEA helps identify measures that are worth investigating in further detail from those that are not relevant and can be discarded. A cost-effectiveness ranking is generally acknowledged to be useful for a first screening, leading to the definition of strategic priorities at the district or regional scales and to the identification of knowledge and data gaps and funding needs.

\begin{tabular}{|c|c|c|c|c|c|c|c|}
\hline $\begin{array}{c}\text { First author } \\
\text { (Year) }\end{array}$ & Country & $\begin{array}{c}\text { Cost } \\
\text { definition }\end{array}$ & Effectiveness & Objective & $\begin{array}{l}\text { Scale of } \\
\text { analysis }\end{array}$ & $\begin{array}{l}\text { Time } \\
\text { step }\end{array}$ & $\begin{array}{c}\text { Type of } \\
\text { measures }\end{array}$ \\
\hline $\begin{array}{l}\text { Berbel et al. } \\
\text { (2009) }\end{array}$ & Spain & $\begin{array}{c}\text { Annual } \\
\text { Equivalent } \\
\text { Cost (AEC) }\end{array}$ & $\begin{array}{l}\text { Pressure and } \\
\text { Impact }\end{array}$ & Deficit & $\begin{array}{l}\text { Water } \\
\text { bodies }\end{array}$ & Annual & $\begin{array}{l}\text { Demand } \\
\text { side }\end{array}$ \\
\hline $\begin{array}{l}\text { Aulong et al. } \\
\text { (2009) }\end{array}$ & Lebanon & $\begin{array}{c}\text { Average } \\
\text { Annualized } \\
\text { Unit Cost } \\
\text { and Average } \\
\text { Incremental } \\
\text { Cost } \\
\end{array}$ & Pressure & Deficit & $\begin{array}{l}\text { River } \\
\text { basin }\end{array}$ & Annual & $\begin{array}{c}\text { Supply and } \\
\text { Demand }\end{array}$ \\
\hline $\begin{array}{c}\text { Rinaudo et al. } \\
(2010)\end{array}$ & France & AEC & Pressure & Deficit & Regional & $\begin{array}{c}\text { Peak } \\
\text { season }\end{array}$ & $\begin{array}{c}\text { Supply and } \\
\text { demand }\end{array}$ \\
\hline $\begin{array}{c}\text { Gerasidi et al. } \\
\text { (2003) }\end{array}$ & Greece & AEC & Pressure & Deficit & Island & $\begin{array}{c}\text { Annual/ } \\
\text { peak }\end{array}$ & $\begin{array}{c}\text { Supply and } \\
\text { network } \\
\text { efficiency }\end{array}$ \\
\hline $\begin{array}{c}\text { El Geriani et } \\
\text { al. } \\
(1998)\end{array}$ & Libya & AEC & Pressure & $\begin{array}{c}\text { Daily } \\
\text { demand }\end{array}$ & Regional & Annual & Supply side \\
\hline
\end{tabular}

Table 1 Some cost-effectiveness analysis applied to quantitative water resources management problems

\subsection{Least-Cost River Basin Optimization Model}

When designing programmes of measures to address water scarcity issues, water managers often need to simultaneously consider several objectives and constraints in the analysis of water resource systems; as 
well as to deal with the temporal and spatial dimensions of the problem. This requires using more complex tools than basic IBCEA, such as integrated water resources modelling approaches. These modelling tools integrate the various components of the problem and assess the impact of the spatial location of the measures on the performance of the water resources system, such as the reliability in supplying water users' demands (Hashimoto, 1982; Martin-Carrasco, 2013). The potential of hydroeconomic models to assess policies and select management measures at the basin scale within the context of the Water Framework Directive is acknowledged in the literature (Heinz, et al., 2007). However, regarding current practices in Europe, few case studies are using such integrated optimization procedures and models for the selection of a programme of measures (ACTEON, 2011, p.20). These models have mainly been implemented to select least-cost combinations of measures to meet water quality standards (Udias et al., 2012; Peña-Haro et al., 2009, 2010; Lescot et al., 2013) or, in a few cases, to define a portfolio of management measures (Padula et al., 2013; Matrosov et al., 2013). At the European scale, a hydro-economic model has been developed to select water efficiency measures to support the next EU water policy development (De Roo, et al., 2012); the limits of such an approach at the European scale are also recognized.

A Least-Cost River Basin Optimization Model (LCRBOM) represents a first approach towards better integrating hydrology, economics and water management. It aims at minimizing the total annualized cost of the programme of measures to meet the environmental flows and water demand targets in several interconnected sub-catchments. In such models, the river basin is represented as a flow network of nodes, interconnected though arcs (links) representing river reaches. At each node, an input-output water flow balance is computed at a given time step. Water management infrastructures (reservoirs, canals, etc.) are represented using lower and upper bound constraints and introducing operational management constraints, while seepage and evaporation losses and return flows are integrated through empirical equations. The variability of surface hydrology is usually represented by long stream-flow time series that reproduce flow conditions at key locations in the basin. Different approaches of varying complexity can be applied to characterize groundwater flow and stream-aquifer interaction, ranging from the simple linear reservoir model to either numerical or analytical solutions of the groundwater flow equation (Pulido-Velazquez et al., 2008 and 2009). This integrated water resources management modelling framework allows the impact of each measure to be characterized in space (each river stretch) and time (given time step) over the whole basin. The optimization is performed for a monthly inflow 
time series representing long successions of wet and dry years and allows the inter- and intra-annual regulation capacity provided by reservoirs or aquifers to be taken into account. 


\subsection{Comparison of the approaches}

The way programmes of measures are selected using both methods can already be summarized conceptually (Figure 1). In the two approaches, the objective is to minimize the total cost $\left(\mathrm{C}_{\mathrm{T}}\right)$ of the programme of measures selected among measures for each demand unit $i$, with $\operatorname{cost} C_{i}$ and effectiveness $\mathrm{e}_{\mathrm{i}}$. The methods differ mainly in terms of their time and spatial representation of the problem. In the IBCEA, the total volume $\left(\mathrm{V}_{\mathrm{T}}\right)$ to be made available by the implementation of the most cost-effective PoM, is calculated as the difference between the total demand $D_{T}$ and the available resources $R_{T}$ (Equation i). This mass balance is assessed for a single time period (e.g. average year, peak conditions) at the basin scale. In the LCRBOM, given the same objective of minimizing $C_{T}$ (Eq. ii), the constraints of the optimization problem are defined at a monthly time step and the spatial resolution is often aligned with the water body or sub-catchment scale. Thus, the mass balance constraint (Eq. iii) ensures that at each node (n) and for each time step (t) the flow going in $\left(\mathrm{I}_{n, t}\right)$ is equal to the flow going out $\left(\mathrm{O}_{n, t}\right)$ and the variation, if any, of the storage in the reservoir $\left(\mathrm{V}_{\mathrm{n}, \mathrm{t}}\right)$. The mass balance involves the necessary data (time series) and/or calculations to properly represent natural inflows, flow releases from surface reservoirs or other hydraulic infrastructures, and return flows from water supply or stream-aquifer interactions. Water outflow from each water body can include seepages to groundwater, evaporation losses or water withdrawals for consumptive uses. Additional constraints are added to ensure that management targets on environmental flows (Eq. iv) and water deliveries to demands (Eq. v) are met at the desired location and time step. Eq. iv states that the in-stream flow in the water bodies (n) must always (at each $t$ ) be higher than minimum environmental flow requirements $\left(E_{n, t}\right)$. Eq. $v$ fixed the objective for a satisfactory supply $\left(\mathrm{s}_{\mathrm{i}, \mathrm{t}}\right)$ of the demand $\left(\mathrm{D}_{\mathrm{i}, \mathrm{t}}\right)$ with the possibility to decrease the demand by applying measures of effectiveness $e_{i}$. At this point, the constraint on water deliveries to the demand can be defined in terms of reliability of the supply, described as the frequency or probability of the system to supply the demand at a given time step (Hashimoto, 1982). While the IBCEA is performed for a fixed larger time step at a lumped basin scale, the LCRBOM analyse a longer period at a monthly time step, disaggregated at the water body or sub-catchment scale. 


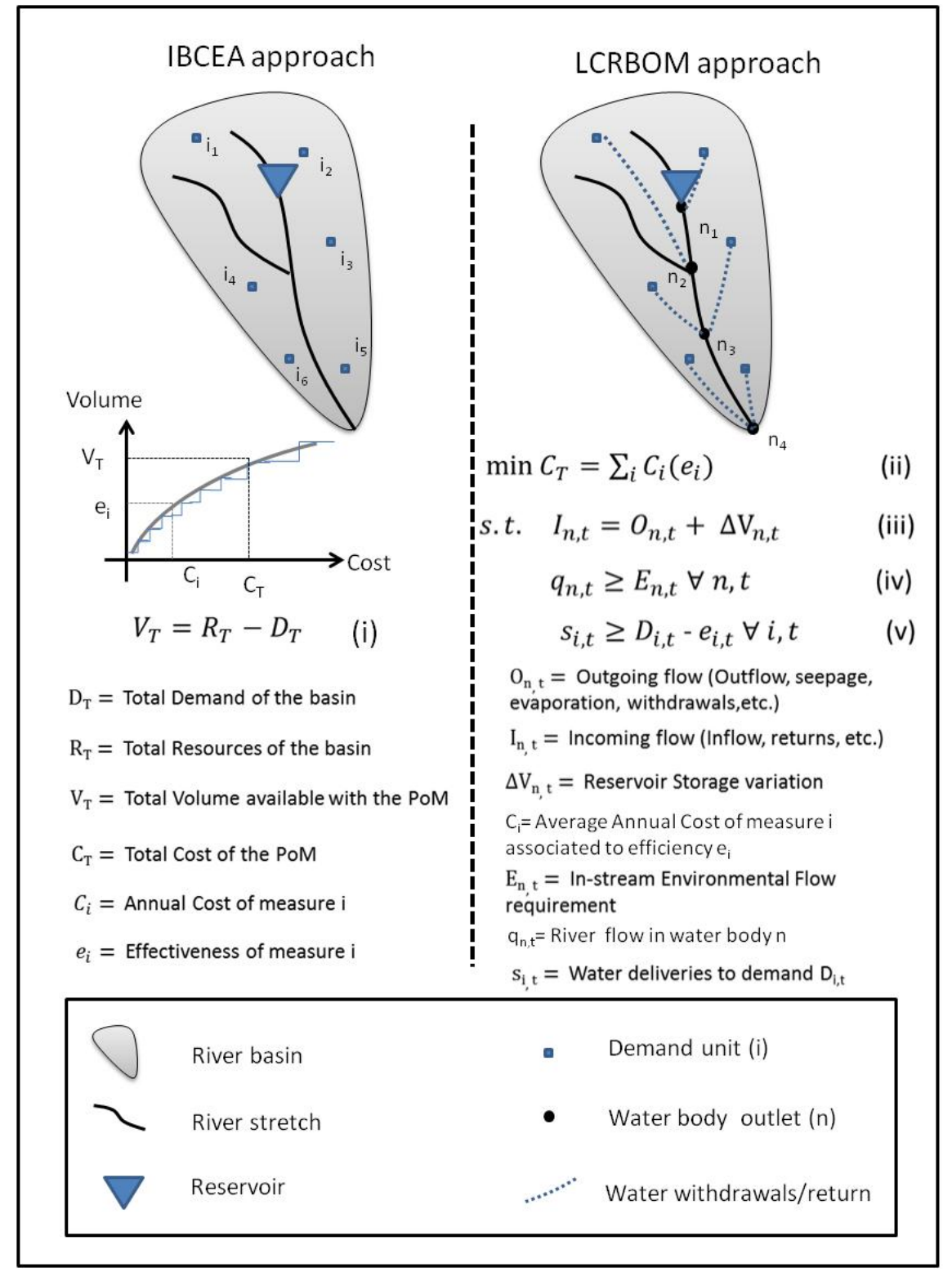

Figure 1 Comparison of the Index-based Cost-Effectiveness Analysis (IBCEA) and the Least-Cost River Basin optimization Model (LCRBOM)

\section{Case study area and policy context: the Orb river basin}

The case study selected for comparing the two methods is the Orb river basin, a $1600 \mathrm{~km}^{2}$ coastal basin in Southern France (Figure 2). This basin is representative of the northern rim of the Mediterranean basin, where water scarcity is an emerging issue. Although managers are increasingly 
aware that water management strategy and practices will need to evolve to cope with the effects of climate change and increasing water demands in the coming 20 or 30 years, adaptation to increased water scarcity is not yet such an issue, unlike in other parts of Southern Europe (e.g. Spain, Cyprus). In this context, preliminary studies have been conducted to anticipate the future evolution of agricultural and urban water demands (Vernier and Rinaudo, 2012), as well as the impact of climate change on local hydrology (Caballero and Girard, 2012). Water abstraction is increasingly regulated to ensure that water resources are exploited within the boundaries of ecosystem sustainability (SMVO, 2013). The next step will consist of defining the strategy that will guide future policy to cope with increased water scarcity. To elaborate this strategy, regional and local stakeholders have shown an interest in a cost-effectiveness analysis of measures, which could be used to bridge the gap between forecasted future water demands and available resources. The present research was implemented in this context. The river basin authority (French Rhône Mediterranean and Corsica River Basin Agency) supported the study with the intention to create a "show case" that could serve a source of inspiration for decision makers of similar basins. The research team started to implement the IBCEA using average cost-effectiveness ratio. The IBCEA was progressively refined to account for spatial heterogeneity, before moving to the development of a LCRBOM. This paper reports on this progressive methodological evolution, together with providing a description of the data, methods and tools that were used. 


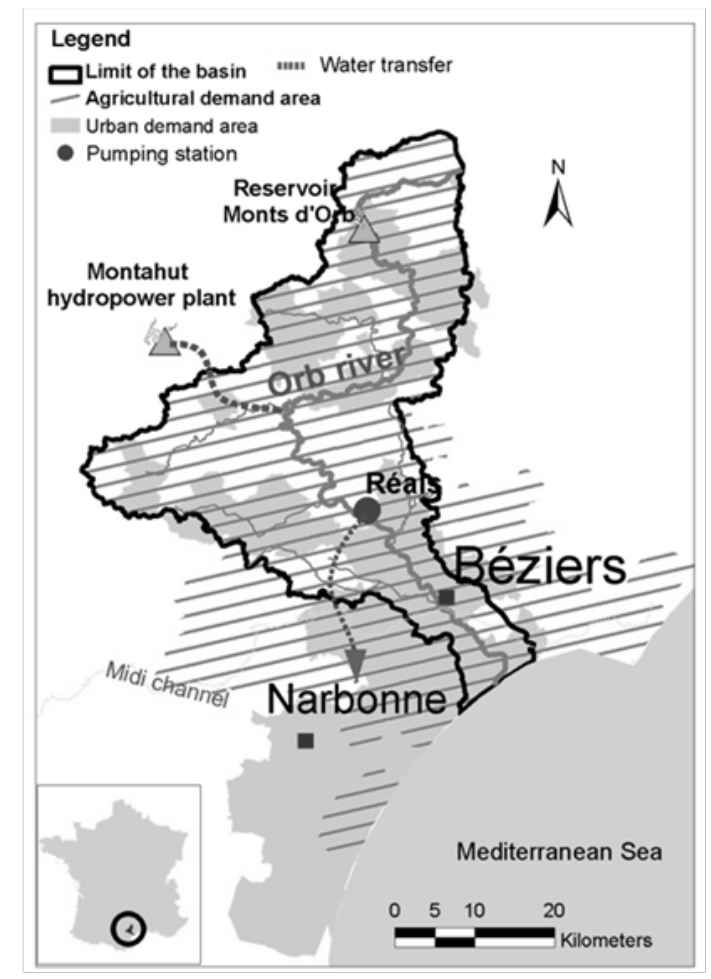

Figure 2 General map of the Orb river basin

\section{Index-based cost-effectiveness analysis in the Orb river basin}

\subsection{Resources and demand estimation: setting the target}

Prior to the selection of the measures, the volume of water to be saved or supplied from alternative resources is estimated as the difference between available resources and demands. In the case study area, water scarcity is mainly a problem during the summer time (from mid-May to mid-September); therefore, the analysis of the deficit was conducted over this period. Future urban water demands were estimated at the 2030 time horizon using an econometric urban water demand model, developed in previous studies (Rinaudo, et al., 2012; Vernier and Rinaudo, 2012). Subsequently, an agro-climatic crop water requirement model (Rinaudo et al., 2013a; Hoang et al., 2012) was used to simulate the impact of future changes in cropping pattern, irrigated area and climatic conditions on the irrigated area dependent on the Orb river basin. On the resources side, the water available during summer time was 
estimated as the 5-years low flow, based on future monthly natural flow generated through a twoparameter monthly rainfall-runoff model, GR2M (Mouehli, et al., 2009) applied on the Orb river basin for the 2046-2065 time period (Caballero and Girard, 2012). In agricultural demand and water resources estimation, climate change was characterized using the results of the global circulation models GFDL CM2 (NOAA, USA) for the emission scenario A1B downscaled following a "weather type" approach (Pagé and Terray, 2010) for the mid-term future period (2046-2065). Environmental flow requirements were derived from existing estimates using a hydraulic habitat model complemented by local expertise (Vier and Aigoui, 2011).

The results of these previous studies have provided the basis to calculate a water resources-demand balance at basin scale for the summer period (Figure 3). It illustrates that, in the current situation, there is no water deficit in the Orb river basin. However, when looking at the future situation and considering the projection of future demand and resources availability under the impact of climate change, a deficit of $4.1 \mathrm{Mm}^{3}$ could appear in a dry summer, challenging the supply of agricultural and urban demands or the level of environmental flows. These projections would have to be considered in the light of the uncertainties associated with climate and demand modelling and evolution scenarios. However, this was beyond the scope of the current comparison (see Girard et al., under review). This volume corresponds to the objective of deficit reduction, defined as step 1 of the IBCEA. 


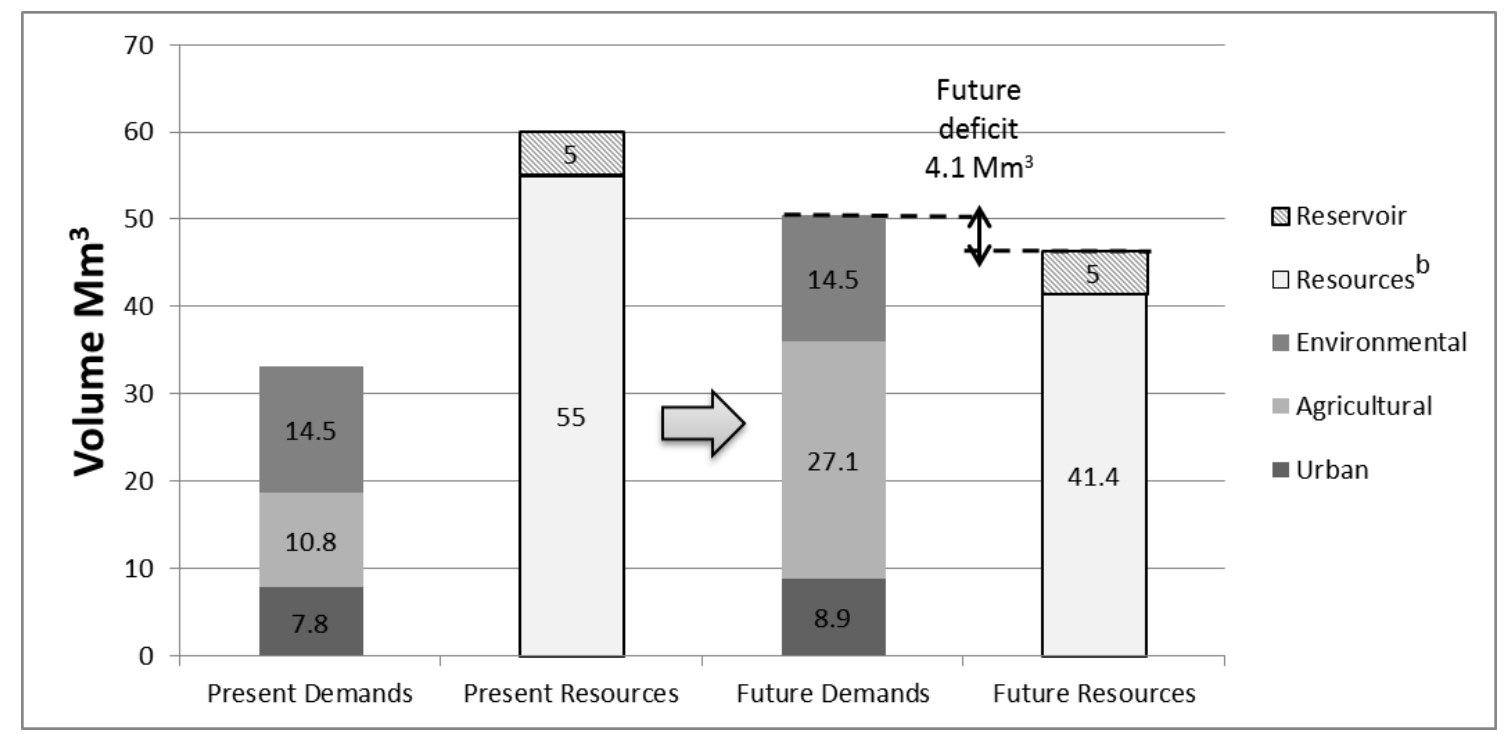

Figure 3 Summer ${ }^{\mathrm{a}}$ water demands and low-flow water resources in the Orb river basin

a. The summer period corresponds to mid-May to mid-September

b. The resources are estimated in this case for a dry year with a return period of 1 out of 5 years

\subsection{Identification and characterization of measures}

After assessing the gap between demand and supply, the second step (step 2) of the IBCEA consisted in identifying potential measures that could be used to fill the gap, and characterizing them in terms of cost and effectiveness. Supply enhancement (capacity expansion) and demand management (water saving) measures were identified in consultation with the stakeholders and by reviewing existing literature, reports and planning documents on the case study area (grey literature). Annualized costs were estimated considering investment and maintenance costs, a technical lifespan for each measure, and a $4 \%$ discount rate as suggested by the French national guidelines (CGP, 2005). Effectiveness was first assessed as the volume of water saved or added (capacity expansion) during the 4 months of the peak demand period (Rinaudo, et al., 2013a).

Nine measures have been defined for the urban water sector, targeting households as main water users, but also other urban water users who have a critical impact on urban peak water demand, such as touristic, municipal and commercial uses (few industries are located in the basin) and park/green spaces uses. All the measures have been designed to potentially be implemented at the same time (mutually 
non-exclusive). However, their effectiveness has been defined only in absolute value (cubic meter saved). Two types of measures have been identified to improve irrigation efficiency (Rinaudo, et al., 2013a).

Measures consisting in sustainably exploiting aquifers not yet in use and not directly connected to the River Orb were also considered. The exploitation cost of these resources was estimated through a detailed analysis of five main implementation projects, considering investment, operation and maintenance costs. The volume of water that can be extracted from these aquifers was estimated by regional groundwater experts (Rinaudo et al., 2013b). The catalogue of measures includes the possibility of building a desalination plant to supply coastal municipalities. Investment and operating costs for such plants were estimated based on figures provided by local engineering companies and cross-checked with values reported in international surveys (Rinaudo et al., 2013a; Zhou and Tol, 2005; Ghaffour et al., 2013).

The results obtained are summarized in table 2, below, which gives a brief description of the generic measure (column 1); the number of demand units (municipalities, irrigation districts) where the specific measure $^{1}$ could be implemented (column 3); and the average cost-effectiveness index (column 3) of generic measures, defined as the average of cost-effectiveness index of all specific measures. This basic information was then used in several ways to support decision making, as discussed in the next section.

\footnotetext{
${ }^{1}$ A specific measure represents the application of one of the generic measures to a specific unit of demand
} 


\begin{tabular}{|c|c|c|c|}
\hline Id & Description of generic measures & $\begin{array}{l}\text { Number of } \\
\text { specific }{ }^{*} \\
\text { measures } \\
\text { applicable }\end{array}$ & $\begin{array}{c}\text { Cost- } \\
\text { effectiveness } \\
\text { index } \\
(€ / \mathrm{m} 3) \\
\end{array}$ \\
\hline \multicolumn{4}{|c|}{ Demand side: water saving measures } \\
\hline MA1 & $\begin{array}{l}\text { Conversion of traditional gravity irrigation systems } \\
\text { to pressurized / sprinkler irrigation. }\end{array}$ & 7 & 0.16 \\
\hline MA2 & $\begin{array}{l}\text { Development of drip irrigation at farm level in } \\
\text { existing piped irrigation networks }\end{array}$ & 11 & 0.54 \\
\hline MU1 & $\begin{array}{l}\text { Improvement of urban supply network efficiency } \\
\text { through detection and repair of leaks }\end{array}$ & 48 & 0.77 \\
\hline MU2 & $\begin{array}{c}\text { Distribution to households of a voucher for free } \\
\text { water conservation devices (faucet aerators + shower } \\
\text { flow reducer). }\end{array}$ & 84 & 0.56 \\
\hline MU3 & $\begin{array}{l}\text { Free water use audit for owners of single-family } \\
\text { houses followed by leakages repair and installation } \\
\text { of water saving devices adapted to the situation }\end{array}$ & 84 & 1.16 \\
\hline MU4 & $\begin{array}{c}\text { Same as U2 for multifamily houses + automated } \\
\text { reading meter. }\end{array}$ & 36 & 1.64 \\
\hline MU5 & $\begin{array}{c}\text { Seasonal water pricing (increased rate in summer) + } \\
\text { automated reading meter. }\end{array}$ & 84 & 0.66 \\
\hline MU6 & $\begin{array}{c}\text { Distribution of water saving devices in hotels (faucet } \\
\text { aerators, toilet flushes). }\end{array}$ & 24 & 0.61 \\
\hline MU7 & $\begin{array}{c}\text { Free water use audits of campsites and holiday } \\
\text { parks. Installation of low flow flushes / showers, } \\
\text { leakage detection in campsite distribution network, } \\
\text { etc. }\end{array}$ & 11 & 1.55 \\
\hline MU8 & $\begin{array}{c}\text { Water intensive landscapes replaced with xeric } \\
\text { vegetation (public gardens) }\end{array}$ & 84 & 0.68 \\
\hline MU9 & $\begin{array}{l}\text { Replacement of irrigated lawns with artificial turf in } \\
\text { sport grounds. }\end{array}$ & 7 & 0.43 \\
\hline \multicolumn{4}{|c|}{ Supply side: capacity expansion project } \\
\hline GW & Groundwater extraction projects & 3 & 1.89 \\
\hline DS & Desalination project & 1 & 1.22 \\
\hline Total & & 484 & \\
\hline
\end{tabular}

Table 2 Description of the measures and average cost-effectiveness index in the Orb river basin

(*A specific measure represents the application of one of the generic measures to a specific unit of demand) 


\subsubsection{Approach 1: Ranking of measures based on their average cost-effectiveness indexes}

First, a simple index-based cost-effectiveness analysis was performed. It consisted of ranking generic measures $(\mathrm{m})$ based on their average cost-effectiveness ratio $(\overline{C E A}(\mathrm{~m}))$, defined as their average cost $\bar{C}(m)$ divided by the average effectiveness $(\bar{e}(m)$, (Equation 1). These were calculated as if the measures were applied to all the corresponding demand units, without looking at specific circumstances likely to change local cost or effectiveness values.

$$
\overline{C E A}(m)=\bar{e}(m) / \bar{C}(m)
$$

Results obtained with this first approach enable the construction of a typical IBCEA curve that depicts the evolution of the cumulated cost and cumulated effectiveness associated with the progressive implementation of the different generic measures (Figure 4). Agricultural measures to modernize irrigation (MA1 and MA2) and measures to improve urban network efficiency (MU1) appear as the most cost-effective on average. At the other extreme, some measures could be discarded based on their high cost per cubic meter (e.g. the introduction of artificial turf, MU9; the distribution of water saving devices for multifamily houses, MU4; or the water audit for individual houses, MU3). The capacity expansion measures (groundwater and desalination) allow a large amount of water to be provided but at high cost, with lower cost-effectiveness. From a policy perspective, the results of this analysis suggest that water conservation measures are more cost-effective than the mobilization of new resources. It also shows that the estimated future gap between demand and available resources can be bridged by a combination of water conservation measures in the urban and agricultural sector, groundwater and desalination development programmes being required only if the gap is greater than expected. A possible use of this type of result, for a river basin authority or a local water committee, could be to prioritize the water conservation measures that appear on the left side of the curve. 


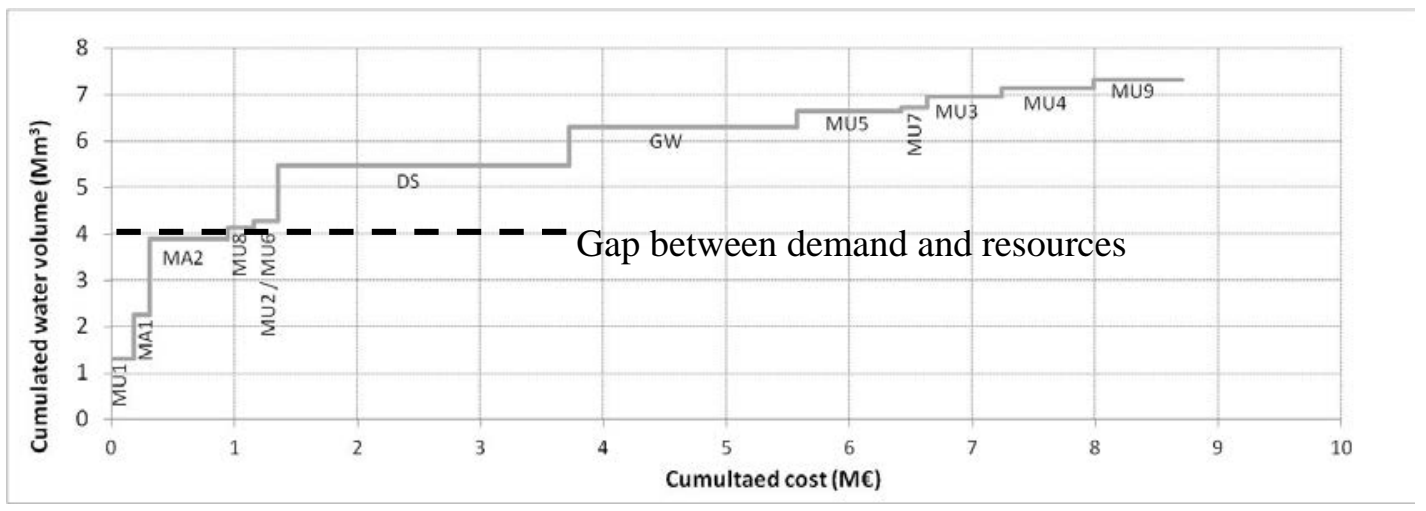

Figure 4 Ranking of the generic measures based on their average cost-effectiveness indexes. The cumulated volume is the sum of volume saved (water conservation measures) or volumes obtained through capacity expansion (groundwater, desalination). The labels used for each measure correspond to those in table 1.

\subsubsection{Approach 2: Considering the spatial heterogeneity of the measures' effectiveness}

However, this simple analysis is not enough to design a programme of measures, specifying where each measure should be implemented. Indeed, this analysis, which considers the average cost-effectiveness indexes of generic measures, conceals the great variability in the cost and effectiveness of specific (local) applications of generic measures. A more sophisticated approach then consist of calculating the cost $C_{m}(i)$ and the effectiveness, $e_{m}(i)$, of each specific measure (m) implemented in each demand unit (i).

$C E A_{m}(i)=e_{m}(i) / C_{m}(i)$

This second approach was implemented in the Orb case study. Results are depicted in Figures 5 and 6. The specific measures are ordered by increasing average cost-effectiveness indexes. Figure 5 highlights that although some generic measures were not found to be cost-effective with an average IBCEA, their implementations in a limited number of specific locations could be worth including in the programme of measures. For instance, the measure of seasonal water pricing (MU5) was less cost-effective on average than MU8, MU2 or MU6, however the $1^{\text {st }}$ quartile of the individual MU5 measures appears to be as, or more, cost-effective than these previous measures. At the opposite end, we find that the implementation of the most cost-effective measures (MU1) in specific location is not cost-effective. Developing a programme of measures based on average index (as described in the previous sub-section) would miss 
the potential of some specific measures, leading to a sub-optimal ranking of measures and generating loss of economic efficiency.
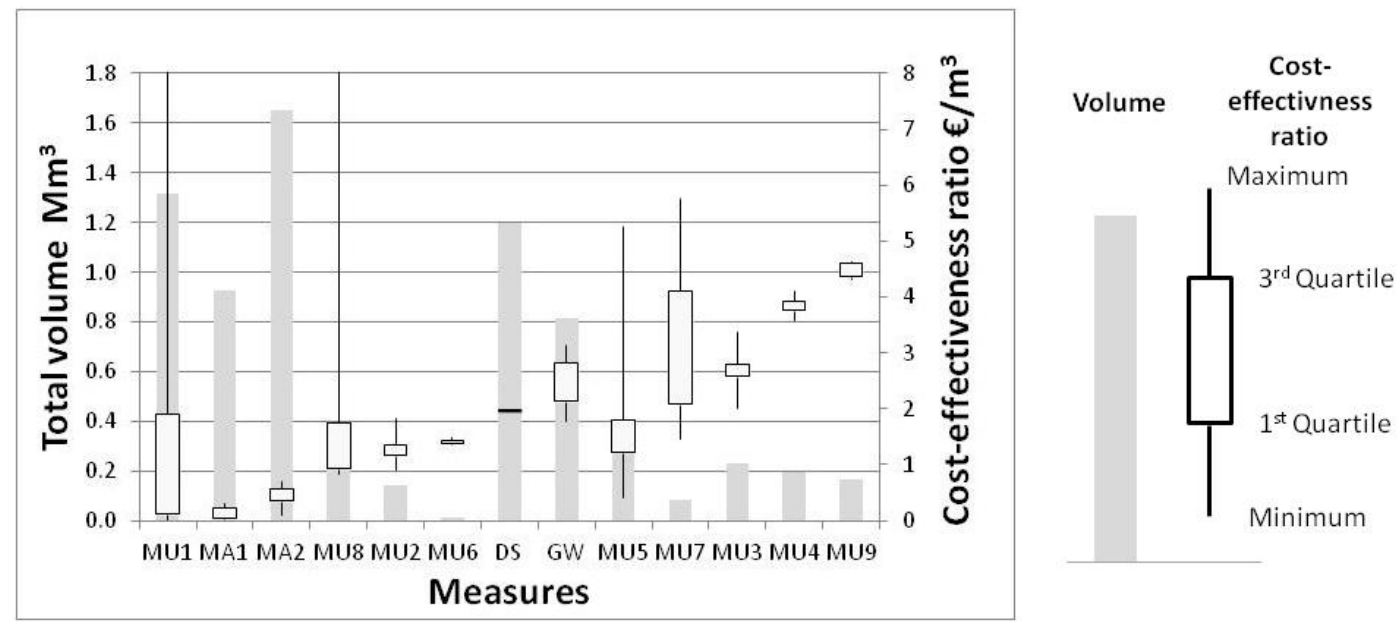

Figure 5 Specific cost-effectiveness statistics for supply and demand measures.

The labels used for each measure correspond to those in table 1

The curves obtained by either looking at average or individual ratio (respectively figure 4 and 6) have a similar shape and the upper-right end point is the same (identical total cumulated cost and effectiveness). However, the curve now provides a ranking of each specific measure considering local circumstances (Figure 6). It thus provides additional information to design an operational plan that would specify in which urban demand unit or irrigation system each measure should be implemented.

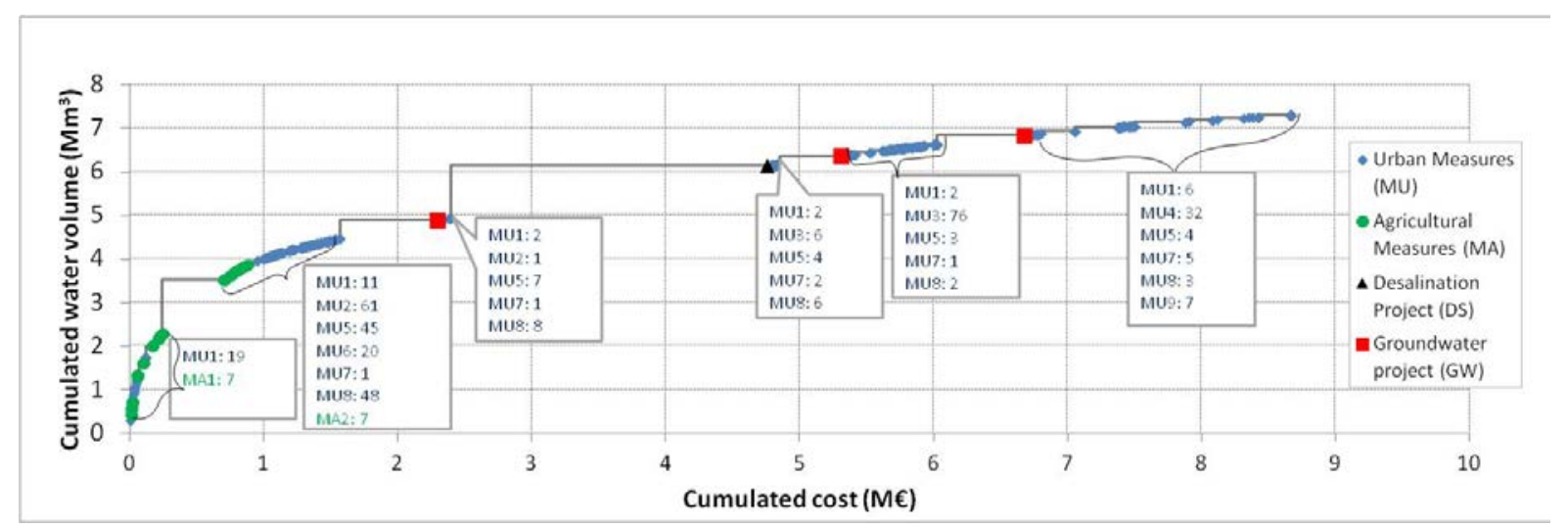

Figure 6 Ranking of the specific measures based on their cost-effectiveness indexes. The cumulated volume is the sum of volume saved (water conservation measures) or obtained through capacity expansion (groundwater or desalination). The labels used for each measure correspond to those in table 1. 


\subsubsection{Approach 3: Modified IBCEA with coefficient for source of supply and return flows}

In the IBCEA approach presented above, the effectiveness of the measures is assessed in terms of reduction of total water abstraction. The problem with that approach is that it neither takes into account return flows, nor the fact that demand units can be supplied by several independent resources. Incorporating these two layers of information may change the results of the analysis and the ranking of measures. Assuming, for instance, that local resources represent only $80 \%$ of the total supply of a demand unit, and that a water conservation measure is implemented to reduce the demand by $20 \%$, the water savings associated with the measure will only be $16 \%$ (20\% of $80 \%$, and not $20 \%)$.

To account for these hydrological connections in the Orb case study, we defined a supply coefficient $\varepsilon_{s}$ and a return flow coefficient $\varepsilon_{\mathrm{r}}$ as parameters (value ranging between 0 and 1 ), for each demand unit $\mathrm{i}$ to represent the percentage of the demand effectively supplied and returned to the water resources system (Equation 3). The value for these parameters were defined based on precedent studies (Ginger, 2011) and validated by local expertise. When no data were available, an average return flow coefficient was applied following the guidance of the river basin authority ( 0.7 for urban demand, 0.8 for upstream open channel irrigation, and no return flows were considered for drip irrigation located outside of the river basin).

$$
C E A_{m+}(i)=e_{m}(i) \times \varepsilon_{r}(i) \times \varepsilon_{s}(i) / C_{m}(i)
$$

The results of this third cost-effectiveness analysis are depicted in Figure 7. Different curves illustrate the differences in results when no hydrological connections are considered (blue full line), only supply connections are considered (green dashed line), and supply and return flow connections are considered (purple dotted line). 


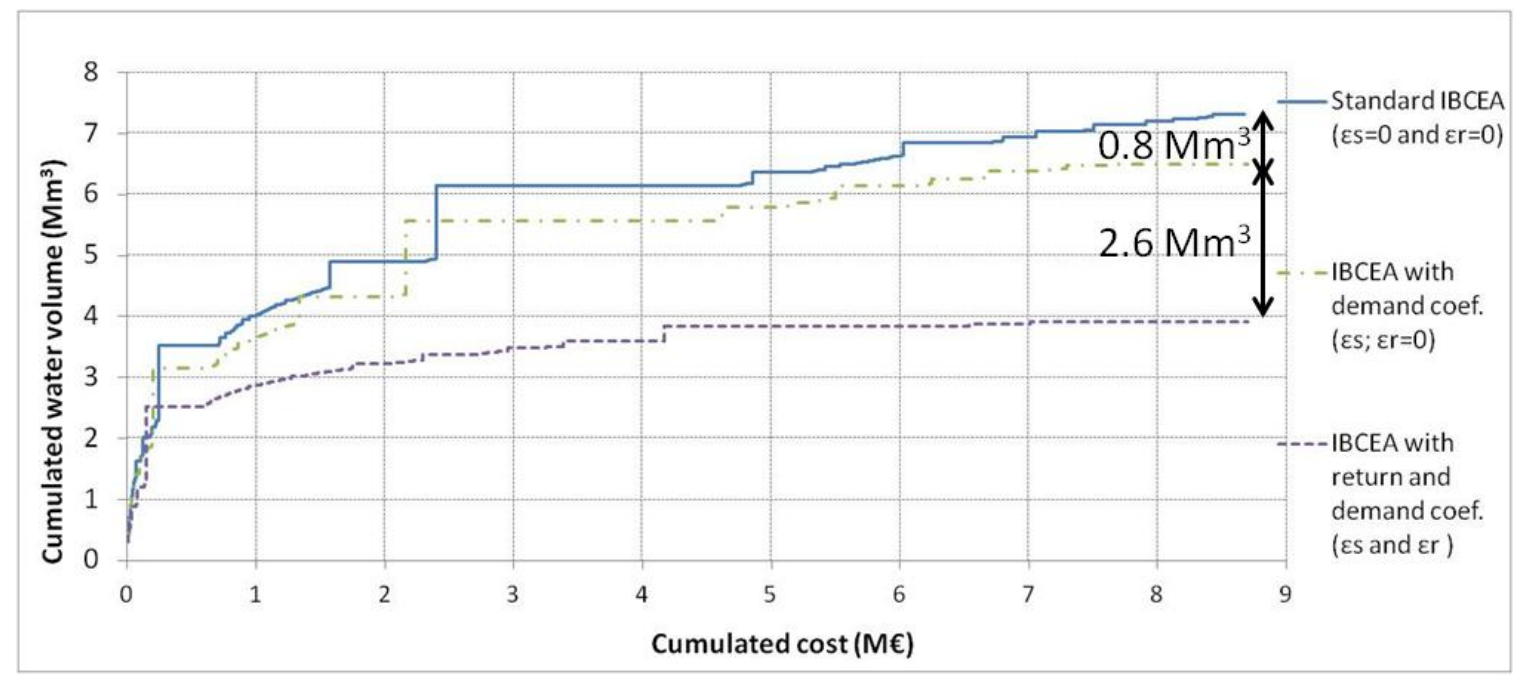

Figure 7 Ranking of the measures based on three different types of Index-Based Cost-Effectiveness Analysis. The cumulated volume is the sum of volume saved (water conservation measures) or obtained through capacity expansion (groundwater or desalination). The labels used for each measure correspond to those in table 1.

In addition to the decrease in efficiency, the ranking of the measures is modified by the definition of effectiveness. The average change in the ranking of a given measure is of 44.9 positions in the ranking (standard deviation 91.7), between the basic IBCEA $\left(\varepsilon_{\mathrm{s}}=\varepsilon_{\mathrm{r}}=0\right)$ and the IBCEA, considering withdrawals $\left(\varepsilon_{\mathrm{s}} \neq 0\right)$; and of 54.8 places (standard deviation 56.7) between the basic IBCEA and the IBCEA considering return flows and withdrawals $\left(\varepsilon_{\mathrm{s}} \neq 0\right.$ and $\left.\varepsilon_{\mathrm{r}} \neq 0\right)$. The variations on the total effectiveness of the measures and on the ranking based on various definition of effectiveness illustrate to what extent the use of pressure based IBCEA could be misleading in the selection of individual measures to be implemented at the basin scale.

\subsection{Limits of an IBCEA in the Orb river basin}

The IBCEA approach presented above is useful for a River Basin Authority, as a first approximation, to define priorities in the design of a programme of measures from an economic efficiency perspective. It provides a first screening of the large number of possible actions; however, the IBCEA faces various limitations when selecting a programme of measures at the basin scale.

First, the time step, either annual or seasonal (4 months in the case study), does not permit the assessment of intra-annual (monthly) deficits of water deliveries to the demands. This also excludes the 
possibility to consider the management of the reservoirs in the water resources systems, moving water over time and hedging releases to deal with water availability imbalances. The IBCEA is a static analysis, whereas the management of the system requires a dynamic approach that considers water resources and demand variability over time.

The spatial scale adopted in the IBCEA, aggregated either at the basin or regional scale, is another great limitation. Selecting measures to tackle a deficit estimated at the basin scale does not ensure that the environmental constraint defined at the water bodies will be met. The IBCEA is still based on pressure reduction and not on the real impact of the measures on the interconnected water bodies in the basin, and therefore does not account for upstream-downstream interactions. Basically, savings upstream will also benefit downstream water users. Because of these limits, the combination of measures resulting for the implementation of an IBCEA is not optimum, either from an economic or a water resources management perspective.

\section{Least-Cost River Basin Optimization Model in the River Orb}

\subsection{Model structure}

To overcome these limitations, a LCRBOM model has been developed on the same information basis. The optimization model is run to select the set of measures that minimizes the total annualized financial cost of a programme of measures $\left(\mathrm{C}_{\mathrm{T}}\right)$ over the selected period. Water management is subject to several constraints in terms of: minimum in-stream flow requirements at the 11 sub-river basins of the Orb river basin; and supply targets for the agricultural and urban demand units. Following the current French legislation (MEEDDT, 2008), all demand must be supplied in at least 4 years out of 5, giving priority to urban and environmental users over agricultural ones. We translate this legal requirement in the following constraints for the optimization model: environmental in-stream flow requirements and urban water demands constraints are met at all times, and agricultural demands should be fully supplied 4 years out of 5 , allowing a deficit 1 year out of 5 . The objective function (Eq. 1 to 3 ) formalizes these assumptions.

Hydrological processes are represented as follows. The sub-river basins are represented as a flow network of 11 nodes interconnected though arcs representing river reaches (Figure 8). It is built up on the same database as the one used for the precedent cost-effectiveness analysis. At each node, a mass 
conservation equation is computed at a monthly time step equalling the total inflow to the node (the runoff of the sub-basin, the river flow coming from the upstream part of the total river basin, the return flows from the supplied Urban and Agricultural Demand Units (UDUs and ADUs respectively) to the total outflow (water supplied to the UDU and ADU, environmental flow, and the remaining additional discharge if any). In the nodes corresponding to a reservoir, the mass balance equation takes into account the seepage and evaporation losses, incorporating constraints on the maximum storage capacity (considering active capacity and flood protection rules). The optimization is carried out over a 20-year monthly flow series integrating successions of wet and dry years. The model has been developed using the General Algebraic Modelling System (GAMS) and applying Mixed Integer Linear Programming based on the solver Cplex (Rosenthal, 2012). The objective function of the optimization problem can be formulated as:

$$
\text { Minimise } C=C_{T}+M \times V_{D}
$$

Where:

$$
\begin{aligned}
C_{T} & =\sum_{\mathrm{m}} \operatorname{Act}(\mathrm{m}) \times \mathrm{FC}(\mathrm{m})+\left(\sum_{\mathrm{t}} \sum_{\mathrm{m}} \mathrm{V}(\mathrm{m}, \mathrm{t}) \times \mathrm{VC}(\mathrm{m})\right) / N \\
V_{D} & =\sum_{t} \sum_{a} D e f_{a, t}^{T^{*}}
\end{aligned}
$$

Where:

$\mathrm{m}$ is an index of the measures of urban or agricultural demand, groundwater or desalination project; $\mathrm{t}$ is the time step index (monthly);

$\operatorname{Act}(m)$ are binary decision variables about implementing (value 1 ) or not implementing (value 0 ) each measure m;

$\mathrm{FC}(m)$ is the fixed equivalent annual cost $(€)$ of the measures, $\mathrm{m}$;

$\mathrm{V}(\mathrm{m}, t)$ is the volume of water in $\mathrm{Mm}^{3} /$ month coming from the groundwater and desalination measures, respectively;

$\mathrm{VC}(m)$ is the variable cost of the groundwater and desalination measures in $€$ per $\mathrm{Mm}^{3}$ per month;

$\mathrm{N}$ is the total number of years of optimization; 
$\mathrm{M}$ is a large positive number that is higher than the sum of the cost of all the other measure, ensuring that measures are applied before a failure to the supply of demand $V_{D}$ is allowed (big-M method to introduce a reliability constraint);

"a" is the index of the ADU,

$\operatorname{Def}_{a, t}^{T^{*}}$ is the deficit for ADU "a" at month " $\mathrm{t}$ " with a return period $\mathrm{T}^{*}$ below the legal requirement (i.e. less than 1 out of 5 years).

As mentioned, the objective function equation is subject to a "mass balance" constraint at all nodes of the network and to capacity constraints at nodes and links. Deliveries for urban demands and environmental flow requirements are integrated in the model as hard constraints, whereas deliveries for the agricultural demands are defined as soft constraints with a penalization in the objective function when not met. The large number of artificial penalty $(M)$ associated to the agricultural deficit $\left(V_{D}\right)$ is just a programming trick (no real economic meaning) to ensure that the system fulfill the legal requirements on the reliability of supply and that measures will be applied prior to any deficit. More details about the formulation of the optimization model can be found in Girard, et al. (2015).

Figure 8 Concept model of Least-Cost River Basin Model in the Orb river basin

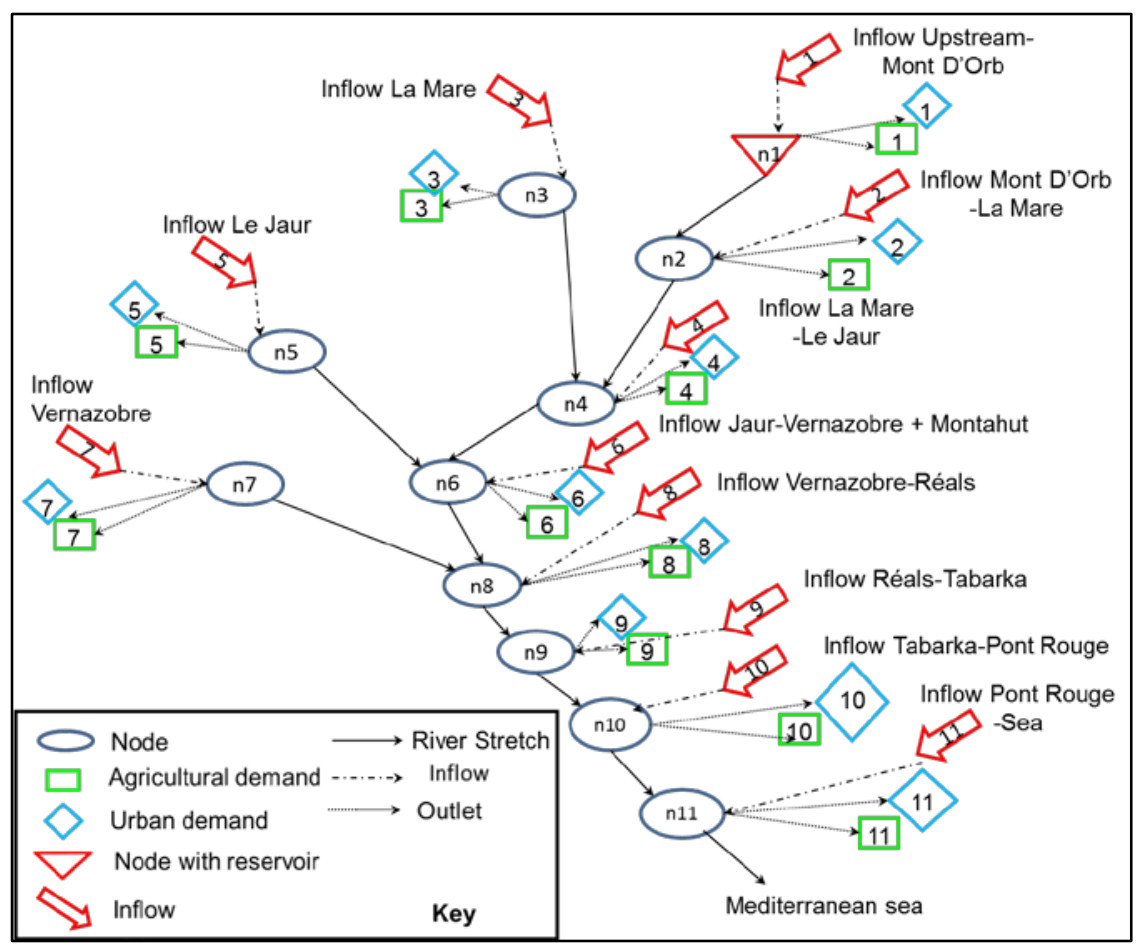




\subsection{Spatial representation: connectivity matrices}

In order to elaborate the LCRBOM, the data used in the IBCEA need to be connected in a consistent spatial framework at the river basin scale. The hydrological nodes are connected through river reaches (Inflow-node matrix) and each urban or agricultural demand is connected to its respective node (demand-node matrix). The main difficulty lays in establishing the link between the UDU, ADU and the water resources (i.e. specifying the value of the supply and return flow coefficient parameter noted $\varepsilon_{\mathrm{r}}$ and $\varepsilon_{s}$, defined in 4.2.3). The connectivity matrices have been established by reviewing the existing studies (Ginger, 2011; BRLi, 2011), and have been validated by local experts in the case of conflicting data.

\section{Results of the LCRBOM and comparison with the IBCEA}

\subsection{Method for comparing the results of the two approaches}

Both the LCRBOM and the IBCEA are used with the purpose of selecting a programme of measures (PoM) at least-cost to achieve management objectives, defined in terms of performance to be achieved by the system under study. We adopt the following notations in this section: PoM' and PoM* respectively refer to the PoM selected by the IBCEA and the LCRBOM, the cost of these PoMs is noted as C' and C* respectively, and the performance indicator of the system where each PoM is applied as I' and I*. The performance indicator selected is an Agricultural Demand Reliability Index (ADRI) that corresponds to the minimum deficit that occurs with a return period lower than 5 years (legal requirement see section 5.1). If ADRI equals 0 then, the legal requirement is fulfilled; otherwise ADRI quantifies the percentage of agricultural demand that is not supplied. ${ }^{2}$

We adopted the following step-by-step process for the comparison (Figure 9):

( First, the LCRBOM is run to select the least-cost programme of measure (PoM*) associated with a total cost C* (Step1).

\footnotetext{
${ }^{2}$ The French law gives full priority to urban demand units which supply can’t be interrupted or reduced. Thus, all deficits are entirely supported by agriculture. This explains why the performance indicator only considers Agricultural deficits.
} 
2 In order to compare the two methods on their performance only, we fixed the cost C' to be equal to the one previously defined, $\mathrm{C}^{\prime}=\mathrm{C}^{*}$ (Step 2).

3 The ranking of measures obtained through CEA is then used to select a PoM' with a cost of C* (step 3).

4 The performance indicators of the two PoMs ( $\mathrm{I}^{*}$ and I') are assessed through a river basin optimization model that optimizes the management of the system (reservoir management) under the implementation of each PoM (step 4) for the same hydrological scenario.

5 The performance of each PoM are compared to assess to which extend the objectives are met under each method at a same annual equivalent cost. 


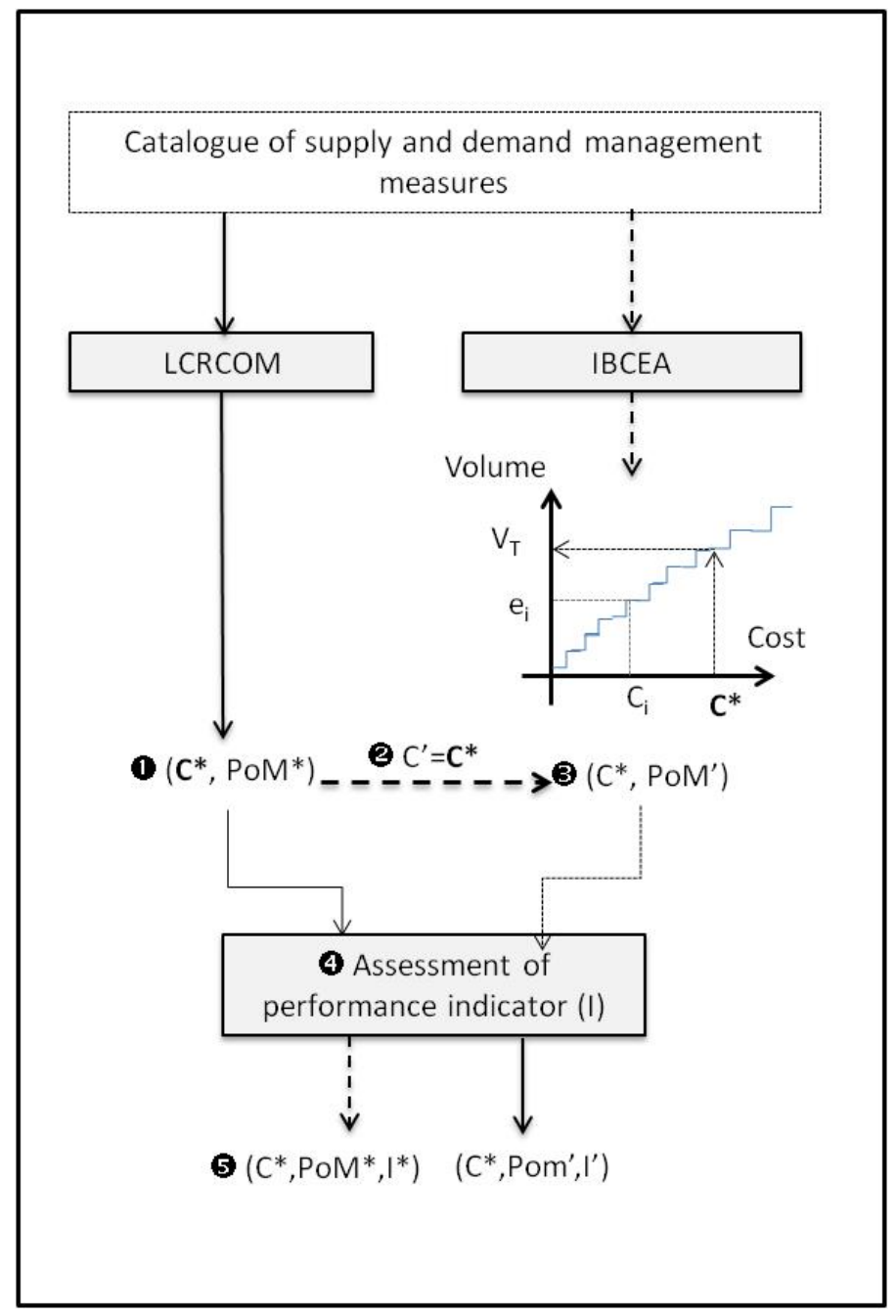

Figure 9 Step-by-step processes to compare the performance of LCRBOM and IBCEA in the selection of a programme of measures at the river basin scale

\subsection{Results of the comparison}

The annual equivalent cost of the PoM identified using the LCRBOM is about $2.5 \mathrm{M} €$. Implementing this PoM enables the full supply of the urban and agricultural demand within the legal requirements and the environmental flow targets to be met. The differences in the measures selected with the LCRBOM and with the IBCEA for the same cost are presented in Table 3 and Figure 9. Both PoM contain all the agricultural measures to modernize irrigation (MA1 and MA2), and most of the network efficiency improvement measures also (MU1). The PoM from the LCRBOM includes the individual household 
auditing measures (MU3) located in the up-stream tributaries of the River Orb. This illustrates how the spatial distribution of the measures is taken into account in the selection of the measures by the LCRBOM and not in the IBCEA. In the LCRBOM, measures are selected locally to ensure objectives at the local water body level, whereas in a basic IBCEA, measures are selected at the river basin scale without accounting for the up-stream-downstream interactions between sub-water bodies. The measures selected by the LCRBOM and applied in the up-stream sub-basins to ensure the supply of the demand and environmental flow requirements also benefit down-stream of the river basin, where less measures are required.

\begin{tabular}{ccc} 
Method & IBCEA & LCRBOM \\
\hline Agricultural measures & 19 & 19 \\
\hline Urban measures & 239 & 140 \\
\hline Ground water project & 1 & 0 \\
\hline Desalination plant project & 0 & 1 \\
\hline Total number of measures & 259 & 160 \\
\hline Total cost & $2.5 \mathrm{M} €$ & $2.5 \mathrm{M} €$
\end{tabular}

Table 3 Comparison of the measures selected by LCRBOM and IBCEA for a same cost 


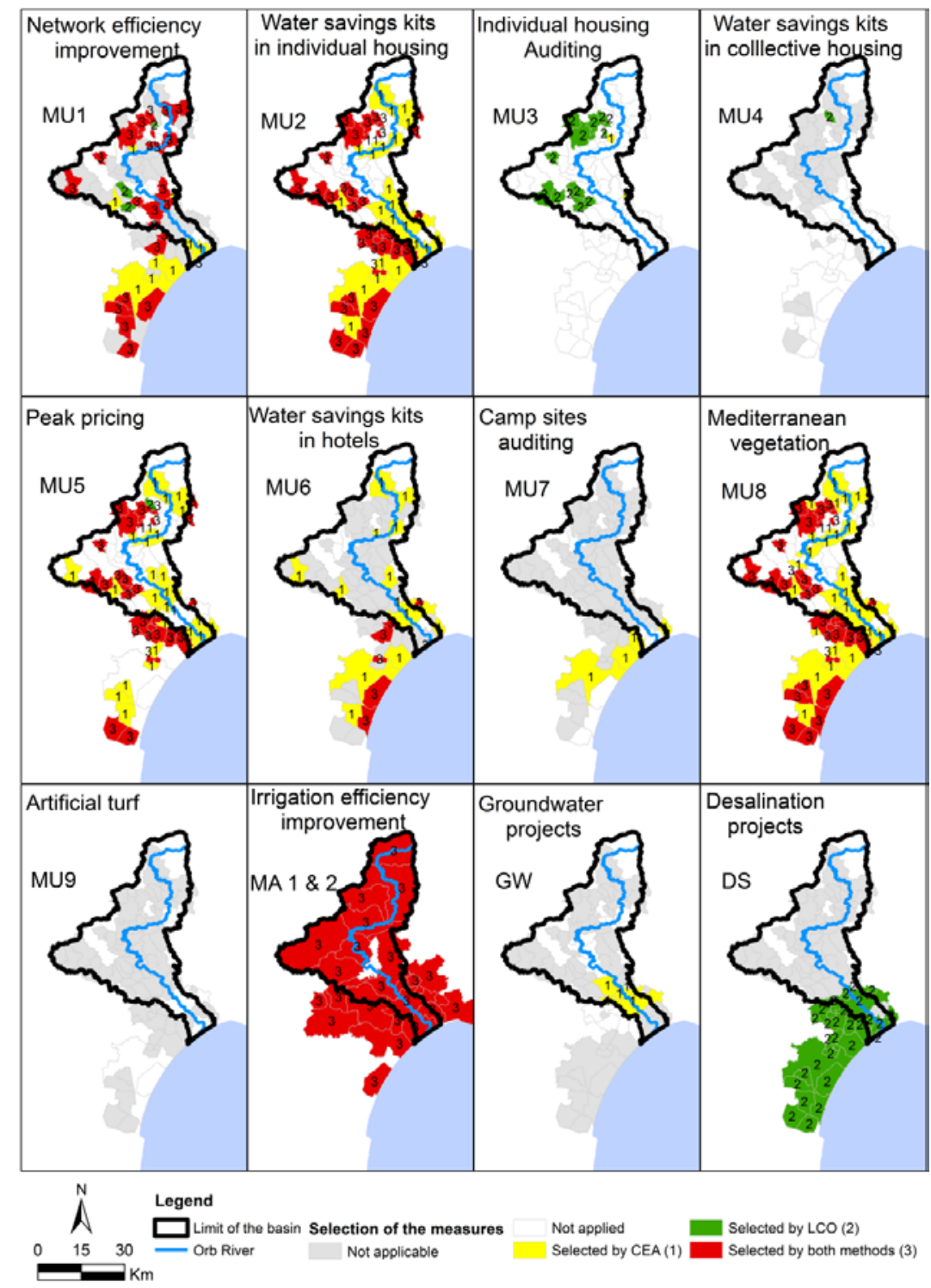

Figure 10 Comparison of the measures selected by an Index-Based Cost-Effectiveness Analysis (CEA) and the LeastCost River Basin Optimization Model (LCO) in the Orb river basin.

The performances of each PoM in terms of agricultural demand reliability index (ADRI) have been calculated under the same hydrological scenario. In all cases, the sub-basins corresponding to the River Orb tributaries, la Mare and le Jaur (M4 and J3), present a high level of deficit (Figure 11), corresponding to a structural deficit already acknowledged in this basin (SMVO, 2013) that do not benefit from the reservoir regulation. In the other basins, whereas the LCRBOM PoM enables a deficit 
to be avoided, implementing the IBCEA PoM results in a deficit in the sub-basins O8 (ADRI=1.2\%) and $\mathrm{O} 12$ (ADRI=23\%). The IBCEA PoM improves the situation but still fails to meet the objective of supplying agricultural demand without deficit in 4 years out 5 in the down-stream part of the basin, as required by the existing regulation. In this sense, the use of the CEA is misleading, as it does not ensure the most cost-effective solution.

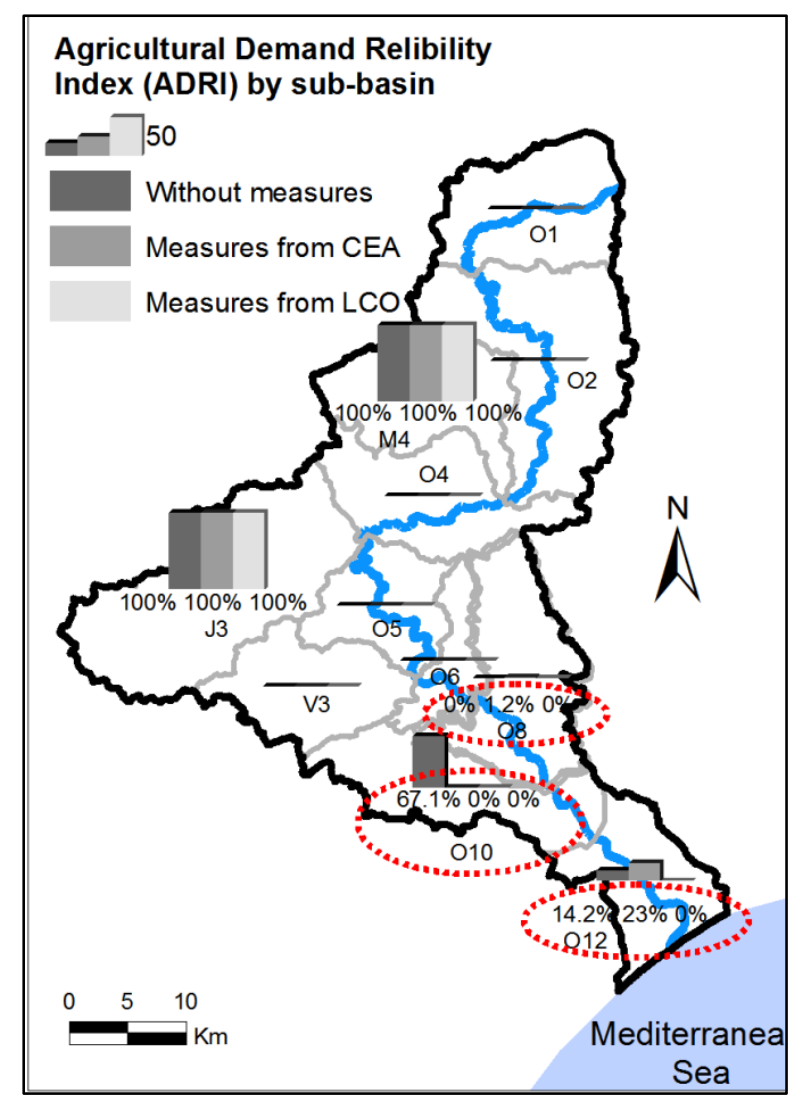

Figure 11 Comparison of the performances (Agricultural Demand Reliability Index) of the Orb water resources system under three different programmes of measures: (1) without measures, (2) applying measures identified using the IndexBased Cost-Effectiveness Analysis and (3) using the Least-Cost River Basin Optimization Model.

\section{Discussion and Conclusion}

The comparison of the Index-Based Cost-Effectiveness Analysis and the Least-Cost River Basin Optimization Model provides some insights on formulating methodological recommendations for the selection of programmes of measures within the implementation of the EU Water Framework Directive. Developing a LCRBOM allows the assessment of the effectiveness of the measures in terms of impacts 
within the interconnected water bodies in a basin, and not only in terms of pressure reduction. Unlike the IBCEA, the LCRBOM allows representing processes such as return flows, up-stream/down-stream interactions, or inter- and intra-annual storage of reservoirs, ensuring a more cost-effective selection of measures in the basin. The management objectives, such as environmental targets or supply of demand, can be set up at the appropriate spatial and temporal scale. Accordingly, it provides more accurate information about the cost and effectiveness of measures to the decision makers concerned with implementing a programme of measures at the basin scale. However, in practice, different conditions are required for the successful implementation of this kind of approach, regarding the state of knowledge of the system, data availability, and time and capacity to develop the model, use it, and communicate its results. For instance, decision makers need to understand the method for it to be relevant to support a decision. Whereas an index-based ranking of measures is something relatively easy to communicate and explain, the processes of modelling and optimizing require additional efforts for it to be shared and accepted.

Then, in terms of science prescriptions, the LCRBOM clearly presents a method that improves and avoids the main failures of the over-simplified basic IBCEA for the implementation of the WFD at the river basin scale. However, the case for the LCRBOM must also be discussed in light of the remaining challenges to be addressed to further implement the Water Framework Directive (Martin-Ortega, 2012), such as improving the integration of an analysis of uncertainty in the decision making process or going beyond a single-criterion analysis.

The analysis of uncertainty in the selection of measures could be improved by the use of integrated water resources models, such as the LCRBOM, as climate and especially hydrological uncertainties can be better assessed by using multi-annual monthly flow time series, rather than low-flow single value statistics in an IBCEA. However, the LCRBOM presented in this study relies on a deterministic optimization process, considering that, for a given hydrological scenario, the future is fully known to the decision maker; what is known as the perfect foresight of the optimization (Labadie, 2004). Under this assumption, the least-cost programme of measures selected can be considered only as the lower bound of the measures that would be needed in the actual implementation to achieve environmental objectives. Further development would therefore be needed, to fully address the issue of the uncertainty in the hydrological time series, not to mention the uncertainties on cost estimations. Moreover, regarding the uncertainties associated with the future impact of climate change on water resources, the use of such a water resources management model provides the possibility to perform an assessment of the best programme of measures under different climate scenarios (Girard et al., under review).

The use of LCRBOM could additionally offer an appropriate framework to address some of the "wicked problems" in the implementation of the WFD, such as the need to question cost-effectiveness analysis as the best decision rule, or addressing the distributional effects of the programme of measures (MartinOrtega, 2012). In the case study presented, the IBCEA and the LCRBOM both rely only on cost minimization criteria. However, the LCRBOM offers interesting possibilities to integrate other 
objectives in a multi-criteria approach and to perform trade-off analysis between environmental and social objectives (see Girard et al. 2015, for a trade-offs analysis between agricultural development, environmental in-stream flow requirement and the cost of the programme of measures).

The LCRBOM does not account for other types of measures such as the transfer of water rights between users, through water markets for instance, on the allocation of water resources, which could be potentially more efficient than the demand and supply management measures presented. On the one hand, simulating voluntary exchanges of water allocation or rights (water market) would require including demand functions for different uses (benefit), through economic demand curves, what is clearly an interesting development of the current model into a full hydro-economic model, but would overpass the framework of a cost-effectiveness analysis. On the other hand, the study is limited to measures fitting the current legal framework, and water markets are not allowed in the French water system

The IBCEA and the LCRBOM both assume that no acceptability or equity issues are interfering in the selection of measures guided only by a single economic efficiency criterion. This assumes a "perfect cooperation" (Madani, 2010) between the stakeholders at the river basin scale that does not reflect the decision making process, where river basin authority decisions are taken in agreement between various stakeholders. The IBCEA or the LCRBOM do not include the equity and distributional aspects of the problem, which suggests that improvements would be needed to account for this part of the problem. Indeed, if the LCRBOM indicates a more cost-effective solution by accounting for the up-stream downstream interactions in the selection of measures, it does not ensure that up-stream users are willing to cooperate on the implementation of measures that will have external benefits to down-stream users.

The use of integrated water resources management models, such as the LCRBOM, can be recommended to improve the economic analysis in the implementation of the Water Framework Directive from a scientific perspective. However, it has to be acknowledged that a clear gap exists between academic recommendations and real application in the context of the WFD, and to avoid this mismatch between science prescriptions and policy application there is a clear need to co-construct knowledge with stakeholders (Martin-Ortega, 2012). The active involvement of the stakeholders beyond the minimum requirements of informing and consulting them during the process of the economic analysis is also a way to improve the effectiveness of the implementation of the WFD (Wright and Fritsch, 2011). The development of models relies on experts, and a top-down development process could impede the operational active involvement of stakeholders and limits the associated increases in the effectiveness of the implementation. However, water resources management models have also proven to be useful in developing some common understanding on water management issues at the river basin scale; for example, supporting the development of shared-vision planning process (Loucks et al., 1985) or participatory modelling exercises (Castelletti and Soncini-Sessa, 2006; Voinov and Bousquet, 2013). The co-construction of knowledge in the development of the model would also be required to overcome the reluctance of decision makers to use economic evaluation methods (Dehnhardt, 2014). 
In the case study presented, the IBCEA was useful as a first step to involve stakeholders who had never been required to make an economic analysis before. Then, once the stakeholders' knowledge and awareness had increased, the method was refined step-by-step, helping them to understand the limitations of IBCEA. We could further develop the full LCRBOM to support the design of an effective operational programme of measures. The model could finally be used as a tool to explore a "space of solutions", as trade-offs between planning objectives and uncertainties associated with climate change. It is thus a method that can be used by stakeholders when they become more "mature". In summary, for the use of scientific tools, such as the LCRBOM, to be successful in supporting water resource planning decisions requires undergoing a learning process with stakeholders and decision makers to co-construct a common representation of the problem and progressively refine the method used, to share the conviction that the tool developed brings some added value to solving a common problem.

\section{Acknowledgments}

This paper is based on work conducted as part of several projects over more than 6 years. It benefited from the financial and technical support of the Agence de l’Eau Rhône Méditeranée et Corse; Conseil Général de l'Hérault; Conseil Régional du Languedoc Roussillon et ONEMA. Funding was partly provided by the IMPADAPT project /CGL2013-48424-C2-1-R) from the Spanish ministry MINECO (Ministerio de Economía y Competitividad) and European FEDER funds. Corentin Girard is supported by a grant from the University Lecturer Training Programme (FPU12/03803) of the Ministry of Education, Culture and Sports of Spain. We are very grateful to Y. Caballero (BRGM), S. Chazot (BRLi), E. Vier and F. Aigoui (GINGERGROUP) and L. Rippert and his team from the SMVOL for their help during the project and for the data provided. We thank as well the two anonymous reviewers, the Associated Editor and Editor-in-Chief of Water Resources Management, for their useful and encouraging comments during the review process.

\section{References}

ACTEON, 2011. Research report on the use of cost-effectiveness analysis in regard to the European water framework directive. Acteon Publishing 2011.

Aulong, S., Bouzit, M., and Dörfliger, N. 2009. Cost-effectiveness analysis of water management measures in two river basins of Jordan and Lebanon. Water Resources Management 23(4): $731-53$

BALANA, B.B., VINTEN, A. and SLEE, B., 2011. A review on cost-effectiveness analysis of agrienvironmental measures related to the EU WFD: Key issues, methods, and applications. Ecological Economics, 70(6), pp. 1021-1031

BERBEL, J., MARTIN-ORTEGA, J. and MESA, P., 2011. A Cost-Effectiveness Analysis of Water-Saving Measures for the Water Framework Directive: The Case of the Guadalquivir River Basin in Southern Spain. Water Resources Management, 25(2), pp. 623-640. 
Brouwer, R. and Hofkes, M., 2008, Integrated hydro-economic modelling: Approaches, key issues and future research directions, Ecological Economics, 66(1), 16-22. doi: 10.1016/j.ecolecon. 2008.02.009

Caballero Y., and Girard C. (2012), Impact du changement climatique sur la ressource en eau du bassin versant de l'Orb. Rapport BRGM/RP-61319-FR. 40 p., 16 ill. (In French) http: //infoterre.brgm.fr/rapports/RP-61319-FR.pdf

Castelletti, A., Soncini-Sessa, R., 2006. A procedural approach to strengthening integration and participation in water resource planning. Environmental Modelling and Software 21, 1455-1470.

CGP (Commissariat Général du Plan), 2005. Révision du Taux d'Actualisation des Investissements Publics, Rapport du groupe d'experts présidé par Daniel Lebègue, Paris

De Roo, A., Burek, P., Gentile, A., Udias, A, Bouraoui, F., Aloe, A. Bianchi, A. La Notte, A., Kuik, O., Elorza Tenreiro, J., Vandecasteele, I., Mubareka, S., Baranzelli, C., Van Der Perk, M., Lavalle, C., Bidoglio, G., 2012. A multi-criteria optimisation of scenarios for the protection of water resources in Europe, Support to the EU Blueprint to Safeguard Europe's Waters, JRC Scientific and policy report, European Commission. http://publications.jrc.ec.europa.eu/repository/handle/111111111/26672

EC (European Commission), 2007. Addressing the challenge of water scarcity and droughts in the European Union. Communication from the Commission to the Council and the European Parliament, $\operatorname{COM}(2007)$ 414, Brussels.

EC (European Commission), 2012. A Blueprint to Safeguard Europe's Water Resources, European Commission, Brussels, 14.11.2012, COM(2012) 673 final.

EEA (European Environment Agency), 2012a. European waters - assessment of status and pressures, EEA Report No 8/2012 ISBN: 978-92-9213-339-9, EEA Copenhagen, 2012 http://www.eea.europa.eu/publications/european-waters-assessment-2012

EEA (European Environment Agency), 2012b. Towards efficient use of water resources in Europe, EEA Report No 1/2012 ISBN: 978-92-9213-275-0, EEA Copenhagen, 2012 http://www.eea.europa.eu/publications/towards-efficient-use- of-water

Garber, A. M. and C. E. Phelps, 1997. Economic foundations of cost-effectiveness analysis, Journal of Health Economics 16: 1-31

Ghaffour, N., Missimer, T.M., Amy, G.L., 2013. Technical review and evaluation of the economics of water desalination: Current and future challenges for better water supply sustainability. Desalination 309, 197-207.

Girard, C., Rinaudo, J.D., Pulido-Velazquez, M., Caballero, Y., 2015. An interdisciplinary modelling framework for selecting adaptation measures at the river basin scale in a global change scenario, Environmental Modelling \& Software , (69), 42-54. http://dx.doi.org/10.1016/j.envsoft.2015.02.023

Girard C., Caballero, Y., Rinaudo, J.-D, and Pulido-Velazquez M., Integrating top-down and bottomup approaches to design global change adaptation at the river basin scale (under review in Global Environmental Change, submitted on the 15/05/2014) 
Griffin, R. C. (1998), The fundamental principles of cost-benefit analysis, Water Resour. Res., 34(8), 2063-2071, doi:10.1029/98WR01335EU-WFD, 2000

Hashimoto, T., Stedinger, J.R., Loucks, D.P., 1982. Reliability, resiliency, and vulnerability criteria for water resource system performance evaluation. Water Resour. Res. 18, 14-20.

Heinz I., Pulido-Velazquez M., Lund J. R., Andreu J. (2007) Hydro-economic modelling in river basin management: Implications and applications for the European water framework directive. Water Resources Management 21, 1103-1125.

Interwies E., Kraemer, A., Kranz, N., Görlach, B, Dworak T., 2004, Basic principles for selecting the most cost-effective combinations of measures for inclusion in the programme of measures as described in Article 11 of the Water Framework Directive-Handbook. Research Report 20221210 UBA-FB 000563/E, Federal Environmental Agency, Berlin, 2004

Interwies, E., Görlach, B., Strosser, P., Ozdemiroglu, E., Brouwer, R., 2005, The case for valuation studies in the Water Framework Directive, Final report, Project WFD55. Sniffer report.

Labadie, J.W., 2004. Optimal operation of multi-reservoir systems: State-of-the-art review. J. Water Resour. Plann. Manage. 130, 93-111.

Lescot, J-M., Bordenave, P., Petit, K., Leccia, O., 2013. A spatially-distributed cost-effectiveness analysis framework for controlling water pollution, Environmental Modelling and Software 41 107122

Loucks, D.P. and E. van Beek (2006). Water Resources Systems Planning and Management: An Introduction to Methods, Models and Applications. Paris: UNESCO.

Loucks, D.P., Kindler, J., Fedra, K., 1985. Interactive water resources modeling and model use: an overview. Water Resour. Res. 21, 95-102.

Madani, K., 2010. Game theory and water resources. J ournal of Hydrology 381, 225-238.

Martin-Carrasco, F., Garrote, L., I glesias, A., Mediero, L., 2013. Diagnosing Causes of Water Scarcity in Complex Water Resources Systems and Identifying Risk Management Actions. Water Resour. Manage. 27, 1693-1705. DOI 10.1007/s11269-012-0081-6

Martin-Ortega, J., Balana, B.B., 2012 Cost-effectiveness analysis in the implementation of the Water Framework directive: A comparative analysis of the United Kingdom and Spain. European Water 37: $15-25$

Martin-Ortega, J., 2012 Economic prescriptions and policy applications in the implementation of the European Water Framework Directive, Environmental science and policy, 24: 83-91

MEEDDT (Ministère de l'écologie, de l'énergie, du développement durable et de l'aménagement du territoire), 2008. Circulaire du 30 juin 2008 relative à la résorption des déficits quantitatifs en matière de prélèvement d'eau et gestion collective des prélèvements d'irrigation NOR : DEVO0815432C, Bulletin officiel du Ministère de l'écologie, de l'énergie, du développement durable et de l'aménagement du terittoire, Paris, 2008 (In French) 
Medellín-Azuara, J.; Harou, J. J.; Olivares, M. A.; Madani, K.; Lund, J. R.; Howitt, R. E.; Tanaka, S. K.; Jenkins, M. W.; Zhu, T. Adaptability and adaptations of California's water supply system to dry climate warming. Clim. Change, 2008, 87, 1, 75-90

Matrosov E.S, Padula, S.and Harou, J. J. 2013 Selecting Portfolios of Water Supply and Demand Management Strategies Under Uncertainty-Contrasting Economic Optimisation and 'Robust Decision Making’ Approaches. Water Resour Manage, 27:1123-1148. DOI 10.1007/s11269-012-0118x

Messner, F., 2006. Guest editorial: Applying participatory multicriteria methods to river basin management: Improving the implementation of the Water Framework Directive. Environment and Planning C: Government and Policy, 24(2), pp. 159-167.

Mollinga, P.P., 2009. Towards the transdisciplinary engineer: Incorporating ecology, equity and democracy concerns into water professionals' attitudes, skills and knowledge. Irrigation and Drainage 58, S195-S204.

Mouelhi, S., Michel, C., Perrin, C., Andréassian, V., 2006. Stepwise development of a two-parameter monthly water balance model. Journal of Hydrology 318, $200-214$. doi: 10.1016/j.jhydrol.2005.06.014

Nash,J.E., and Sutcliffe,J.V., 1970. River flow forecasting through conceptual models, J. Hydrol., 10(3), 282-290.

Newlin, B. D., M. W. Jenkins, J. R. Lund, and R. E. Howitt, 2002. Southern California water markets: Potential and limitations, J. Water Resour. Plann. Manage., 128(1), 21- 32.

O'Laoghaire, D. T., and Himmelblau, D. M., 1974. Optimal expansion of a water resources system. - With 273 pp. New York and London: Academic Press. ISBN 0-12-525450-4.

Pagé, C. and Terray, L., 2010. Nouvelles projections climatiques à échelle fine sur la France pour le 21ème siècle : les scénarii SCRATCH2010. Technical Report TR/CMGC/10/58, SUC au CERFACS, URA CERFACS/CNRS No1875CS, Toulouse, France (http://www.cerfacs.fr/ page/work/scratch/). (In French)

Poff, N.L., Allan, J.D., Bain, M.B., Karr, J.R., Prestegaard, K.L., Richter, B.D., Sparks, R.E., Stromberg, J.C., 1997. The natural flow regime: A paradigm for river conservation and restoration. Bioscience 47, 769-784.

Pohl, C., 2005. Transdisciplinary collaboration in environmental research. Futures 37, 1159-1178.

Postel S. Richter B., 2003. Rivers for Life: Managing Water for People and Nature. Island Press, Washington, DC.

Pouget, L., Escaler, I., Guiu, R., Mc Ennis, S., Versini, P.-., 2012. Global Change adaptation in water resources management: The Water Change project. Sci. Total Environ. 440, 186-193.

Pulido-Velazquez, M., M. W. Jenkins, and J. R. Lund, 2004, Economic values for conjunctive use and water banking in southern California, Water Resour. Res., 40, W03401, doi: 10.1029/2003WR002626 
Pulido-Velazquez, M., Andreu, J., Sahuquillo, A., Pulido-Velazquez, D., 2008. Hydro-economic river basin modelling: The application of a holistic surface-groundwater model to assess opportunity costs of water use in Spain. Ecol. Econ. 66, 51-65.

Pulido-Velazquez, M., Alvarez-Mendiola, E., Andreu, J., 2013. Design of efficient water pricing policies integrating basinwide resource opportunity costs. J. Water Resour. Plann. Manage. 139, 583592.

Pushpalatha, R., Perrin, C., Le Moine, N., Andréassian, V., 2012. A review of efficiency criteria suitable for evaluating low-flow simulations, Journal of Hydrology 420-421 171-182, doi: 10.1016/j.jhydrol.2011.11.055

Quevauviller,P.; Barceló,D.; Beniston,M.; Djordjevic,S.; Harding,R.J.; I glesias,A.; Ludwig,R.; Navarra,A.; Navarro Ortega,A.; Mark,O.; Roson,R.; Sempere,D.; Stoffel,M.; van Lanen,H.A.J.; Werner,M.; 2012, Integration of research advances in modelling and monitoring in support of WFD river basin management planning in the context of climate change. Sci.Total Environ., 440, 167-177

Padula, S., Harou, J.J., Papageorgiou, L. G., Ji, Y., Ahmad, M., Hepworth, N., 2013 Least Economic Cost Regional Water Supply Planning-Optimising Infrastructure Investments and Demand Management for South East England's 17.6 Million People, Water Resources Management 27:50175044, DOI 10.1007/s11269-013-0437-6

Peña-Haro, S., Llopis-Albert, C., Pulido-Velázquez, M., Pulido-Velázquez, D., 2010. Fertilizer standards for controlling groundwater nitrate pollution from agriculture: El Salobral-Los Llanos case study, Spain. J. Hydrol. 392: 174- 187.

Peña-Haro, S., M. Pulido-Velazquez, A. Sahuquillo, 2009. A hydro-economic modelling framework for optimal management of groundwater nitrate pollution from agriculture. Journal of Hydrology 373 , pp. 193-203.

Pulido-Velázquez, M., Sahuquillo, A., and J. Andreu, 2006. Economic optimization of conjunctive use of surface and groundwater at the basin scale. J. Water Resour. Plan. Manage., 132(6), 454-467.

Pulido-Velázquez, M., Andreu, J., Sahuquillo, A., Pulido-Velazquez, D., 2008. Hydro-economic river basin modelling: The application of a holistic surface-groundwater model to assess opportunity costs of water use in Spain. Ecological Economics, 66(1), 51-65

Rinaudo J-D and Aulong S (2014) Defining groundwater remediation objectives with cost-benefit analysis: does it work ? Water Resources management. 28(1) 261-278.

Rinaudo JD, Girard C., Vernier de Byans C, (2013a), Analyse coût efficacité du programme de mesures de gestion quantitative : Application de deux méthodes au bassin versant de l'Orb Rapport BRGM. Available at http://infoterre. brgm.fr/rapports/RP-62713-FR.pdf (In French)

Rinaudo, J-D, Noel, Y., Marchal, J.-P., Lamotte, C., (2013b). Evaluation du coût de mobilisation de nouvelles ressources en eau souterraine dans l'Ouest de l'Hérault. Rapport BRGM-RP- 61794-FR http://infoterre.brgm.fr/rapports/RP-61794-FR.pdf (In French)

ROSENTHAL, E., 2012. GAMS, A User's Guide Tutorial by Richard E. Rosenthal , GAMS Development Corporation, Washington, DC, USA 
SMVO (Syndicat Mixte de la Vallée de l'Orb), 2013. Contrat de rivière Orb-Libron, 2011-2015, Dossier définitif, Dossier M001 803039 / EV. http://www.vallees-orb-libron.fr/wpcontent/uploads/2012/12/dossier-definitif-contrat-riviere-orb-libron-11-15.pdf (In French)

Udías,A.; Efremov,R.; Galbiati,L.; Cañamón,I. 2012 Simulation and multicriteria optimization modeling approach for regional water restoration management. Annals of Operations Research, 1-18

VAN ENGELEN, D., SEIDELIN, C., VAN DER VEEREN, R., BARTON, D.N. and QUEB, K., 2008. Costeffectiveness analysis for the implementation of the EU Water Framework Directive. Water Policy, 10(3), pp. 207-220.

Vernier de Byans, M. and Rinaudo JD (2012) Scénarios d'évolution de la demande en eau potable à I'horizon 2030 dans l'Ouest Hérault. Rapport BRGM/RP-61317-FR.Brgm : Orléans. $51 \mathrm{p}+$ ann. Available at http://infoterre.brgm.fr/rapports/RP-61317-FR.pdf

Voinov, A., Bousquet, F., 2010. Modelling with stakeholders. Environmental Modelling and Software $25,1268-1281$.

Ward, F.A., 2009. Economics in integrated water management. Environmental Modelling and Software 24 (8), 948-958.

WATECO (WORKING GROUP 2.6), 2003. Common implementation strategy for the Water Framework Directive (2000/60/EC). Guidance Document no.1.Economics and the Environment - The implementation Challenge of the Water Framework Directive.

White SB, Fane SA, Robinson D (2003) The use of levelised cost in comparing supply and demand side options for water supply and wastewater treatment. Water Supply 3(3):185-192

Wurbs, R.A. 1996 Modeling and Analysis of Reservoir System Operation, Prentice Hall, ISBN 0136059244

Zhou, Y., Tol, R.S.J., 2005. Evaluating the costs of desalination and water transport. Water Resour. Res. 41, 1-10. 